\title{
Five-year Survey Uncovers Extensive Diversity and Temporal Fluctuations Among Fusarium Head Blight Pathogens of Wheat and Barley in Brazil
}

\author{
C. B. Pereira ${ }^{1}$ - T. J. Ward² • E. M. Del Ponte ${ }^{3}$ - G. M. Moreira ${ }^{3}$ - M. Busman² - S. P. McCormick ${ }^{2}$ • \\ H. R. Feksa, ${ }^{1,4}$ J. L. De Almeida ${ }^{4}$ • D. J. Tessmann ${ }^{1}$
}

\section{Affiliations:}

1 Departamento de Agronomia, Universidade Estadual de Maringá, Maringá, Paraná 87020-900, Brazil

2 Mycotoxin Prevention and Applied Microbiology Research Unit, National Center for Agricultural Utilization Research, Agricultural Research Service, US Department of Agriculture, Peoria, Illinois 61604-3999, USA

3 Departamento de Fitopatologia, Universidade Federal de Viçosa, Viçosa, MG 36570-900, Brazil

4 Fundação Agrária de Pesquisa Agropecuária - FAPA, Guarapuava, PR 85139-400, Brazil

\section{Funding:}

This study was financed in part by the Coordenação de Aperfeiçoamento de Pessoal de Nivel Superior - Brasil (CAPES) - Finance Code 001, for a scholarship for the first author, and also by the Fundação Agrária de Pesquisa Agropecuária (FAPA), Cooperativa Agrária Agroindustrial, and the Brazilian National Council for Scientific and Technological Development (CNPQ project 310719/2016-6). Funding was also provided by the USDA-ARS National Program for Food Safety.

\section{Data and reproducibility:}

Data and code for reproducibility are available at https://emdelponte.github.io/paper-Fusarium-PR

\section{Author for correspondence:}

D. J. Tessmann

ditessmann@uem.br

Keywords: Fusarium avenaceum, Fusarium poae, Fusarium head blight, Hordeum vulgare, mycotoxin, Triticum aestivum.

\section{Abstract}

We conducted a five-year survey (2011-2015) of barley and wheat fields in Paraná state, Brazil, analyzing 754 Fusarium isolates from Fusarium head blight (FHB)-symptomatic spikes. Multilocus genotyping and TEF- $1 \alpha$ gene sequence analyses confirmed the dominance of the F. graminearum species complex (75.7\%), but F. poae (11.5\%) as well as F. avenaceum and related members of the $\mathrm{F}$. tricinctum species complex (FTSC, 8.1\%) appeared as substantial contributors to FHB. Within the FGSC, F. graminearum of the 15-ADON genotype was dominant (63\%), followed by F. meridionale of the NIV genotype (23.1\%), F. cortaderiae of the NIV (7\%) or 3-ADON (2.6\%) genotypes, and F. austroamericanum (3.8\%) of the 3-ADON genotype. Substantial variation in pathogen composition was observed across years, with $\mathrm{F}$. poae and $\mathrm{F}$. meridionale frequencies significantly elevated in some years. Most F. poae strains produced DAS, diANIV and butenolide, but not Neosolaniol, T-2 or HT-2. All FTSC species produced moniliformin. Enniatin production was widespread among FTSC species, with the single F. acuminatum strain found to be the strongest producer of enniatins. Our findings confirm FGSC as a major contributor to FHB and expand considerably our knowledge of the presence, frequency and conditions under which other pathogens may emerge altering the spectrum of toxins that may accumulate in grain. 


\section{Introduction}

Fusarium head blight (FHB) is a disease of major economic concern to wheat and barley growers due to the potential to reduce yield and contaminate grain with mycotoxins at levels that lead to grain downgrade or rejection by food and brewing industries (Goswami and Kistler, 2004; McMullen et al., 2012). The disease manifests on the wheat heads as a result of infections by airborne spores of Fusarium spp. that land on the plant during flowering and early grain development stages (Del Ponte et al. 2007; Yoshida and Nakajima, 2010). Among several species of Fusarium that are pathogenic to these cereals, species of the F. graminearum species complex (FGSC) such as F. graminearum and F. asiaticum, are regarded as the main FHB pathogens worldwide, including in Brazil (Del Ponte et al., 2015). The FGSC is a subset of the broader F. sambucinum species complex (FSAMSC), which includes species such as F. poae that are also commonly associated with FHB in some regions. In addition, F. avenaceum and other members of the F. tricinctum species complex (FTSC) are known to contribute to FHB epidemics, mainly in temperate regions (Gräfenhan et al., 2013; O'Donnell et al., 2013; Bec et al., 2015).

The main concern with the presence of multiple toxigenic species relates to the wider range of mycotoxins that they may produce in grain. For instance, FGSC strains are known to produce B-trichothecenes, but subtypes can been determined for each strain given their ability to produce deoxynivalenol (DON) or nivalenol (NIV), and their respective acetylated forms 3-acetyl(A)DON (3-ADON chemotype), 15-ADON (15-ADON chemotype) and 4,15di-ANIV (NIV chemotype) (Savard et al., 1991). Recently, a subpopulation of F. graminearum has been found to produce the type A trichothecene NX-2 (NX chemotype) instead of DON or NIV (Varga et al., 2015). The genes responsible for the differential production of these toxins have been identified and assays have been developed to reliably 
predict toxin type based on DNA sequence differences (Ward et al., 2002; Liang et al., 2014; Garmendia et al., 2018). FGSC are also known to produce zearalenone, but differences among the species of the complex are still unknown. FTSC strains can produce moniliformin (MON) and a series of cyclic depsipeptides such as enniatin analogues (ENs) and beauvericin (BEA) (Jestoi et al., 2008; Luz et al., 2017). On the other hand, F. poae can produce NIV and type A trichothecenes in addition to BEA (Vanheule et al., 2017).

In Brazil, molecular surveys since the mid-2000s have contributed to understanding FGSC diversity associated with FHB in wheat (Scoz et al., 2009; Astolfi et al., 2012; Del Ponte et al., 2015) and barley (Astolfi et al., 2011; Castañares et al., 2016; Machado et al., 2017). For those crops, F. graminearum is the dominant species from the FGSC ( $>80 \%$ frequency) along with four other DON or NIV-producing species within the complex. Expanding these molecular surveys to other major cereal crops documented host-specific differences in the relative prevalence of FGSC species. For instance, F. meridionale dominates in maize stalk and ear rots (Kuhnem et al., 2015) and F. asiaticum dominates in rice kernels (Gomes et al., 2015). Collectively, these studies suggest that FGSC composition and toxigenic profile are strongly shaped by host and regional factors. For example, F. meridionale was found to be a more significant contributor to FHB of wheat in Paraná state, where maize production is more common, than in Rio Grande do Sul (RS) state (Del Ponte et al., 2015). In addition, there is evidence of a possible cultivar effect shaping the composition of FGSC species, as was demonstrated recently for barley grown in RS state (Machado et al., 2017).

Previous studies of FHB in Brazil have largely focused on the diversity within the FGSC. Little is known about the presence and relative contributions of other species to FHB of wheat and barley in Brazil despite the potential significance of this variation for disease and mycotoxin control programs. In this study, we conducted a five-year survey of 
FHB diversity in the central-south wheat-producing area of Paraná state, Brazil. This is one of the most important wheat and barley production regions in South America and was not well represented in previous studies. In addition to documenting the species and mycotoxin diversity associated with FHB in this region, the results were used to test the hypotheses that host or year of sampling drive pathogen composition.

\section{Material and methods}

\section{Survey area, seasons and sampling}

During five consecutive growing seasons (2011 to 2015), commercial wheat and barley fields from the central/south region of Paraná State Brazil were visited during the grain filling period and heads exhibiting FHB symptoms were manually harvested. The minimum and maximum distance between two fields was $26.2 \mathrm{~km}$ and $237 \mathrm{~km}$, respectively. The fields were located within the latitudes of -24.45 to -26.05 and longitudes of -51.45 to -52.16 encompassing 17 municipalities. The wheat and barley fields were cultivated under no-till following soybean as summer crop.

\section{Fungal isolation, purification and DNA extraction}

All kernels were excised from each head and the Fusarium-damaged kernels selected for isolations. These were surface sterilized in $70 \%$ ethanol for $1 \mathrm{~min}$, immersed in $1 \%$ sodium hypochlorite for $1 \mathrm{~min}$, and rinsed three times with autoclaved distilled water. After drying, kernels were placed on top of wet filter paper inside a germination box and incubated for seven days at $20{ }^{\circ} \mathrm{C} \pm 2{ }^{\circ} \mathrm{C}$ with a 12 hours light/dark cycle. Fragments of mycelia from a 
typical Fusarium spp. colony grown on the kernels were transferred to water agar (WA) medium and sub-cultured onto a synthetic low-nutrient agar (SNA) using a single spore (Leslie and Summerell, 2006). Isolates were frozen at $-80{ }^{\circ} \mathrm{C}$ in $20 \%$ glycerol for long-term storage at the U. S. Department of Agriculture, Peoria, IL and at the Universidade Estadual de Maringá. A mycelial plug was transferred from the purified colonies to 6-cm petri plates containing V8 agar and incubated at $26{ }^{\circ} \mathrm{C}$ for seven to 15 days. Mycelia were harvested with scalpel blades and stored at $-20{ }^{\circ} \mathrm{C}$. Total genomic DNA was extracted using the Quick-DNA $^{\mathrm{TM}}$ Fungal/Bacterial 96 Kit (Zymo Research) according to manufacturer's instructions.

\section{Species identification}

Species and trichothecene genotypes were identified for FGSC isolates using a multilocus genotyping (MLGT) assay (Ward et al., 2008). The MLGT is based on allele-specific primer extension (ASPE) reactions targeting single nucleotide polymorphisms (SNPs) for the discrimination of 16 species within the FGSC, five related species, and their associated trichothecene types (Ward et al., 2008; Garmendia et al., 2018). Sequences of the partial translation elongation factor (TEF-1 $\alpha$ ) gene were obtained using previously published primers (O'Donnell et al., 1998) for all isolates that failed identification in the MLGT assay. Polymerase chain reaction (PCR) was carried out in a final volume of $25 \mu \mathrm{L}$ containing $50 \mathrm{ng}$ of genomic DNA and 10x PCR Buffer, $50 \mathrm{mM} \mathrm{MgSO}_{4}, 10 \mathrm{mM}$ of deoxynucleoside triphosphate, $0.6 \mathrm{mM}$ each primer, $5 \mathrm{U}$ of Platinum Taq High Fidelity polymerase (Invitrogen). PCR conditions were: initial denaturation for 2 min at $96{ }^{\circ} \mathrm{C}$ followed by 35 cycles of $30 \mathrm{~s}$ at $94{ }^{\circ} \mathrm{C}, 15 \mathrm{~s}$ at $53{ }^{\circ} \mathrm{C}, 45 \mathrm{~s}$ at $68^{\circ} \mathrm{C}$. PCR products were analyzed on a $1 \%$ agarose gel and were purified with Millipore MultiScreen-PCR96 filter plates (Millipore). 
Sequencing reactions were performed using Big Dye Terminator Sequencing kit v3.1 (Applied Biosystems) and analyzed with an ABI 3730 DNA Analyzer (Applied Biosystems). Sequences were edited and aligned manually using SeqAssem (Hepperle, 2004). Isolates were identified to the species level using sequence similarity searches of the Fusarium $\begin{array}{llll}\text { MLST (http://www.cbs.knaw.nl/fusarium/) and Fusarium ID } & \text { and }\end{array}$ (http://isolate.fusariumdb.org/blast.php) databases (Geiser et al, 2004; O'Donnell et al., 2010). Species identifications were applied when query sequences had at least $99 \%$ sequence similarity with reference sequences.

\section{Analysis of species composition and frequency}

Descriptive statistics summarized species composition and frequency between hosts and among years. The chi-square independence test $\left(\chi^{2}\right)$ or Fisher's exact test (for small sample size) were used to evaluate differences in species composition in specifics comparison. All data processing and analyses, as well as graphical work, were performed running $\mathrm{R}$ version 3.6 .0 (2019-04-26) (R Core Team, 2019). To encourage and facilitate reproducibility, a website (https://emdelponte.github.io/paper-Fusarium-PR/) was generated to navigate through the documented code and all files are freely available and permanently stored as an Open Science Framework project available at https://osf.io/dzc9h/

\section{Phylogenetic analysis of FTSC isolates}

Phylogenetic analysis was conducted using TEF-1 $\alpha$ sequences from FTSC isolates identified in this study and 50 reference isolates (Niessen et al., 2012; O'Donnell et al., 2012; 
Gräfenhan et al., 2013; Lysøe et al., 2014; Cerón-Bustamante et al., 2018; Moreira et al., 2019). DNA sequences were edited with SeqAssem (Hepperle, 2004) and aligned using the MUSCLE algorithm implemented in MEGA X (Kumar et al., 2018). Phylogenetic analysis was also conducted in MEGA using maximum likelihood with the $\mathrm{K} 2+\mathrm{G}$ model of molecular evolution as determined by Bayesian Information Criterion (BIC) scores. Branch support was assessed via bootstrap analysis employing 1000 pseudoreplicates of the data.

\section{Mycotoxin analysis}

Isolates were screened for production of mycotoxins by inoculation on cracked maize kernels $(25 \mathrm{~g}+11 \mathrm{ml}$ water) as previously described (Aoki et al. 2015). After $14 \mathrm{~d}$ incubation in the dark, $10 \mathrm{~g}$ of each culture was extracted with $20 \mathrm{ml}$ 86:14 (v/v) acetonitrile:water for 30 min with shaking. After the extracts were clarified via filtration, they were analyzed by high-performance liquid chromatography-mass spectrometry (HPLC-MS), using a ThermoDionex Ultimate U3000 liquid chromatograph (ThermoScientific) coupled to a Thermo Exactive high resolution mass spectrometer (ThermoScientific). A $0.6 \mathrm{ml} / \mathrm{min}$ reverse-phase gradient (40\%-95\%) flow between acetonitrile and water over 5 min was used to elute fungal metabolites from a $50 \mathrm{~mm}$ x $2 \mathrm{~mm} \mathrm{C18}$ column (Kinetex XB-C18, $2.6 \mu \mathrm{m}$ particle size, $10 \mathrm{~nm}$ pore size; Phenomenex). HPLC-MS analyses were conducted in positive electrospray ionization mode to detect mycotoxins. HPLC-MS comparisons of ion mass and elution time with purified standards were used to identify the metabolites (Busman et al., 2012; Busman, 2017). Limits of quantitation for aurofusarin, beauvericin, enniatin B, enniatin B1, enniatin A and enniatin A1 were $1 \mathrm{ng} / \mu \mathrm{l}$.

\section{Toxin production in liquid culture}

F. poae strains were screened for trichothecenes, culmorin, and butenolide production in a liquid medium that induces trichothecene production. Each strain was initially grown on 
V8 juice agar plates (20\% V8 juice, 0.3\% CaCO3, 2\% agar; Stevens, 1974). Twenty ml of agmatine media (30 g sucrose, $1.14 \mathrm{~g}$ agmatine, $1 \mathrm{~g} \mathrm{KH}_{2} \mathrm{PO}_{4}, 0.5 \mathrm{~g} \mathrm{MgSO} 4-7 \mathrm{H}_{2} \mathrm{O}, 0.5 \mathrm{~g} \mathrm{KCl}, 10$ mg $\mathrm{FeSO}_{4}-7 \mathrm{H}_{2} \mathrm{O}$ ) and $200 \mu \mathrm{l}$ of trace element solution (per $100 \mathrm{ml}: 5 \mathrm{~g}$ citric acid, $5 \mathrm{~g}$ $\left.\mathrm{ZnSO}_{4}-7 \mathrm{H}_{2} \mathrm{O}, 0.25 \mathrm{~g} \mathrm{CuSO}_{4}-5 \mathrm{H}_{2} \mathrm{O}, 50 \mathrm{mg} \mathrm{MnSO}_{4}-\mathrm{H}_{2} \mathrm{O}, 50 \mathrm{mg} \mathrm{H}_{3} \mathrm{BO}_{3}, 50 \mathrm{mg} \mathrm{NaMoO}{ }_{4}-2 \mathrm{H}_{2} \mathrm{O}\right)$ per $1 \mathrm{~L}$ distilled water (Gardiner et al., 2009) in $50 \mathrm{ml}$ Erlenmeyer flasks were inoculated with two $0.5 \mathrm{~cm}^{2}$ plugs cut from V8 plates. The cultures were grown at $28{ }^{\circ} \mathrm{C}$ on a rotary shaker at $200 \mathrm{rpm}$ in the dark. After seven days each culture was transferred to a $50 \mathrm{ml}$ conical tube and extracted with $8 \mathrm{ml}$ ethyl acetate with shaking for $30 \mathrm{~min}$. The mixture was separated with centrifugation $(3000 \mathrm{rpm})$ and the top ethyl acetate layer was transferred to 1 dram vial and dried under a nitrogen stream. The residue was then re-suspended in $1 \mathrm{ml}$ ethyl acetate for GC-MS.

GC-MS analyses were performed with an Agilent 5873 fitted with an HP-5MS column $(30 \mathrm{~m}, 0.25 \mathrm{~mm}, 0.25 \mu \mathrm{m})$, and detected with a mass spectrometer with an electron impact source. Helium was used as the carrier gas with a $20: 1$ split ratio and a $20 \mathrm{ml} / \mathrm{min}$ split flow. Samples were injected at $150{ }^{\circ} \mathrm{C}$, the temperature held for $1 \mathrm{~min}$ and then the column was heated at $30{ }^{\circ} \mathrm{C} / \mathrm{min}$ to $280{ }^{\circ} \mathrm{C}$ and then held for $7.7 \mathrm{~min}$. Individual peaks in chromatograms were examined for trichothecenes. Under these conditions, T-2 toxin is detected at $10.6 \mathrm{~min}$, neosolaniol at $8.5 \mathrm{~min}, 4,15$ - diANIV at $8.1 \mathrm{~min}, 4,15$-DAS at $7.4 \mathrm{~min}$, 15ADON at $7.1 \mathrm{~min}$, and butenolide at $3.1 \mathrm{~min}$. All chromatographic peaks were examined and identified based on comparison of retention time and ion fragmentation patterns with a commercial NIST library and a library prepared with purified standards. Extracted ion chromatograms were generated to screen for any components with a prominent $\mathrm{m} / \mathrm{z} 121$ ion, characteristic of T-2 toxin, neosolaniol and related compounds. The limit of detection was $0.25 \mu \mathrm{g}$ toxin/ml culture. 


\section{Results}

\section{Species diversity}

A total of 754 isolates of Fusarium spp. were obtained from symptomatic spikes. The number of isolates was similar between the hosts (Figure 1a), but variable across years; the lowest sample size was obtained from $2011(n=54)$ and the highest from $2014(n=295)$ (Figure 1b). Isolates were identified as members of nine species or species complexes (Figure 1c), among which FGSC accounted for the majority of isolates and occurred at similar frequencies between the hosts $(79.9 \%$ and $72.4 \%$ of the wheat and barley strains, respectively). The second most prevalent species overall was F. poae recovered more frequently from barley (14.5\%) than wheat (7.8\%) followed by FTSC isolates found in similar frequency in wheat (7.5\%) and barley (8.5\%) (Figure 1c). Members of the FIESC and FFSC were represented each by around $2 \%$ of all isolates from both hosts. The isolates of $\mathrm{F}$. cerealis were obtained from wheat and the single-isolate representatives of the F. oxysporum species complex (FOSC), F. subtropicale, and F. armeniacum, were obtained from barley (Figure 1a,2b). No significant relationship between the frequencies of the nine species/complexes and host (wheat or barley) (Fisher's exact test, $\mathrm{P}=0.071$ ). 


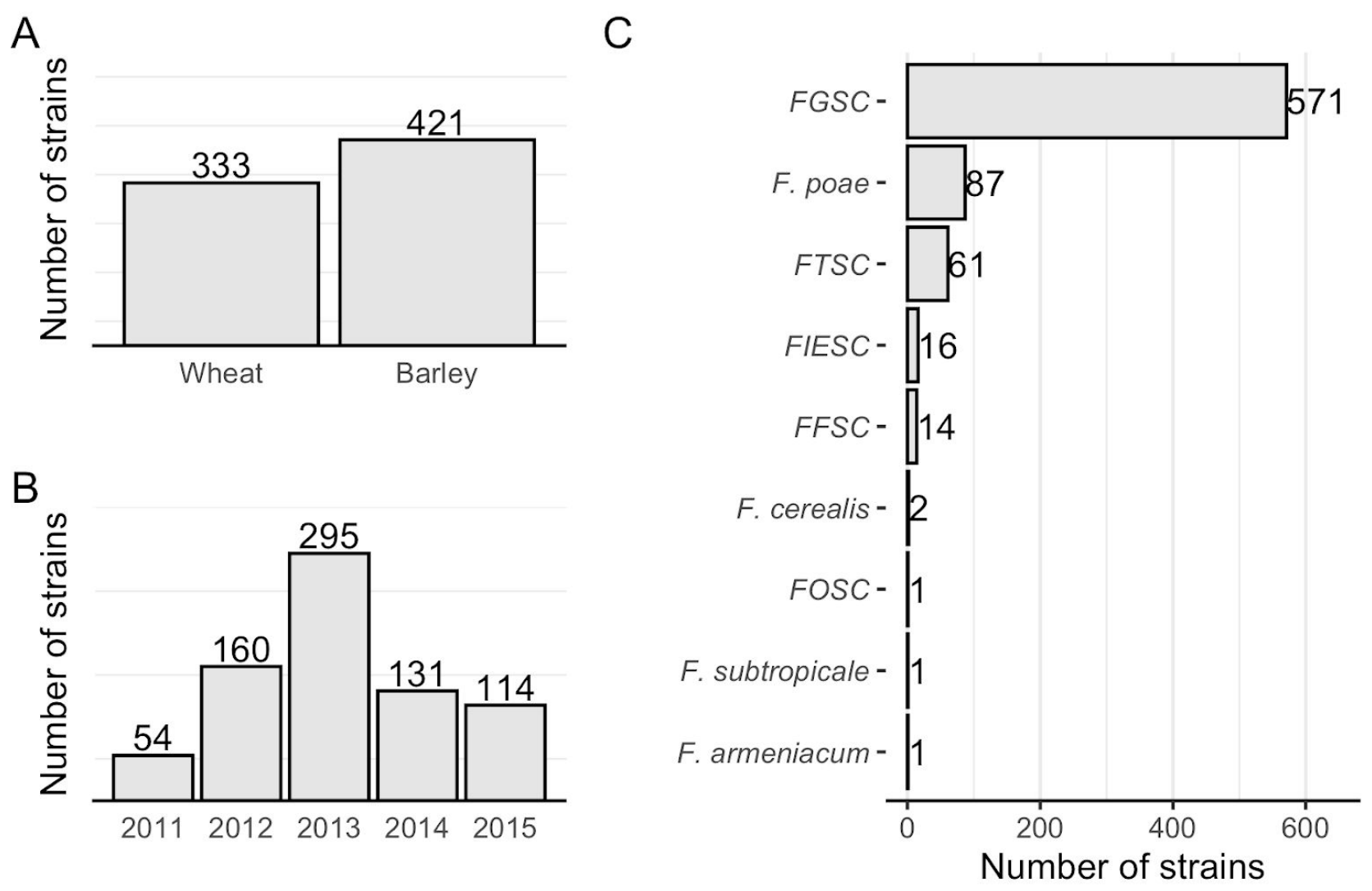

Figure 1. Number of Fusarium spp. isolates in relation to host of origin (A) and cropping seasons (B) obtained from symptomatic heads sampled in wheat and barley fields sampled at several fields in the Guarapuava region, Paraná State Brazil, during five years. Isolates were identified as members of nine species or species complexes using DNA sequence-based methods $(\mathrm{C})$

\section{Yearly frequency of Fusarium spp.}

The frequencies of the species/complexes of the two host in combination, were dependent on the year (Fishser's exact test, $P<0.001$ ) FGSC accounted for the majority of isolates in each of the five years; their frequencies ranged from 51.9 to $92.4 \%$ regardless of the host. Fusarium poae was present in all collections except wheat from 2001. Three distinct peaks 
in frequency of F. poae were observed in isolates from wheat in 2013 (Figure 2a) and from barley in 2012 and 2013 (Figure 2b). A slight increase in FFSC was also observed in 2012 (Figure 2a,b). While FTSC was present in all years, FIESC occurred more sporadically but also peaked in 2012 in isolates from both hosts, similar to FFSC (Figure 2). The rare species (others) were collectively observed in four out of the five years.

A

Wheat $(n=366)$

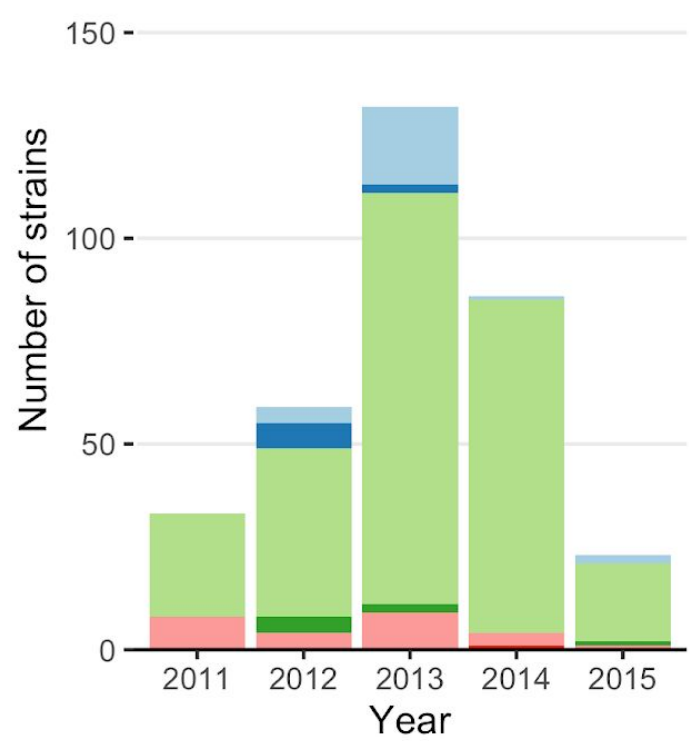

B

$$
\text { Barley }(n=421)
$$

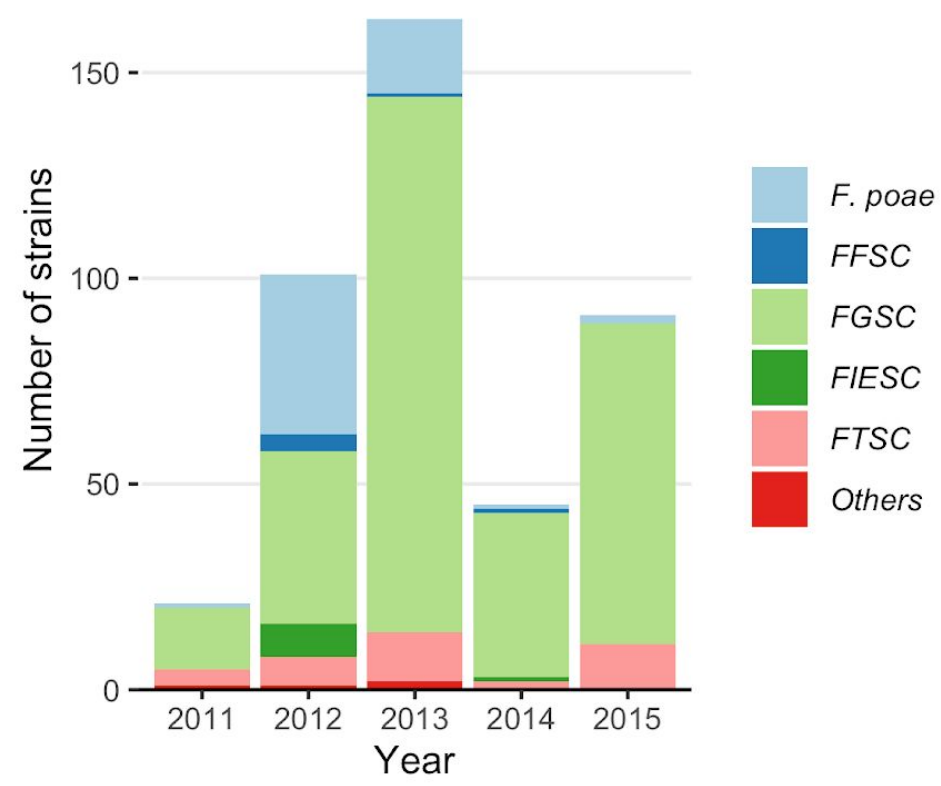

Figure 2. Relative yearly frequencies of Fusarium species complex/species in a collection of 754 isolates obtained from heads of wheat (A) and barley (B) conditioned host of origin: $\mathrm{FFSC}=\mathrm{F}$. fujikuroi species complex; FGSC $=$ F. graminearum species complex; FIESC $=\mathrm{F}$. incarnatum-equiseti species complex and FTSC $=$ F. tricinctum species complex; Others $=$ F . subtropicale, F. armeniacum and FOSC (F. oxysporum species complex) 


\section{FGSC composition and toxin genotypes}

Four species were identified in the sub-collection of 571 FGSC isolates from both hosts. Among them, F. graminearum dominated the collection (63.3\%) followed by F. meridionale (23.1\%), F. cortaderiae (9.6\%) and F. austroamericanum (3.8\%) (data not shown). Differences in their relative frequencies in wheat and barley were not statistically significant $\left(\chi^{2}=7.40\right.$; $\mathrm{P}=0.06$ ). For example, frequencies of $\mathrm{F}$. graminearum were $58 \%$ and $69 \%$ in barley and wheat, and of F. meridionale were 26 and 19\% in barley and wheat, respectively.

The four species were found in all years regardless of the difference in sample size. Their frequencies, wheat and barley combined, varied among the year (Fisher's exact test, $\mathrm{P}$ $<0.001)$. Fusarium graminearum was dominant in most year-host combinations, but its relative frequency was slightly reduced in 2012 and 2013, years when F. meridionale peaked in both hosts but was more evident in barley (Figure 3a,b). A slight increase of $\mathrm{F}$. meridionale was also noted in 2015 in barley (Figure 3b). A single toxin type was observed for all species but F. cortaderiae isolates, which were either NIV (73\%) or DON (27\%). F. graminearum were all of the 15-ADON type, and all F. meridionale and F. austroamericanum isolates were of the NIV type.

\section{FTSC diversity}

Comparison of TEF- $1 \alpha$ sequences with reference sequences in the Fusarium MLST database suggested three FTSC species in the collection of 61 isolates. The results of phylogenetic analysis were consistent with the species identifications derived from Fusarium MLST. Three well-supported clades (Bootstrap $\geq 87 \%$ ) were formed. The largest one included 51 F. avenaceum, 30 in wheat (Figure 4a) and 21 in barley (Figure 4b). The 
second in frequency was FTSC11 with nine isolates (five from wheat and four from barley). F. acuminatum was represented by a single isolate collected in wheat in 2013. F. avenaceum was found in all but one season at frequency ranging from two to nine isolates and FTSC11 was found in all but two years in barley and all but one in wheat (Figure 4).

A

Wheat $(n=266)$

$$
125-
$$

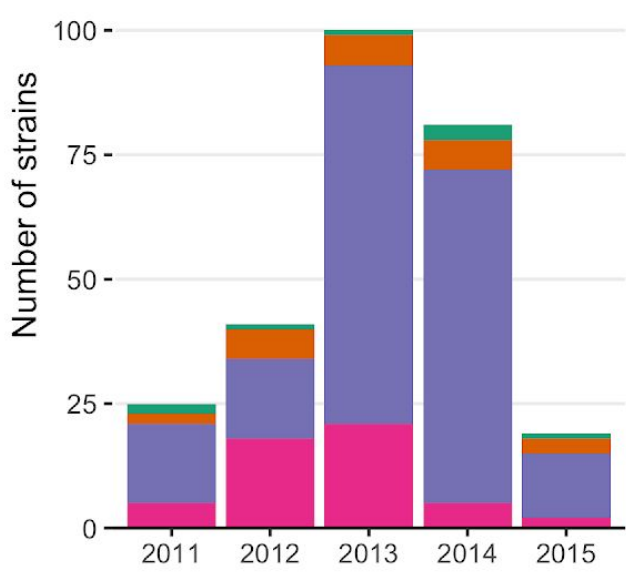

B

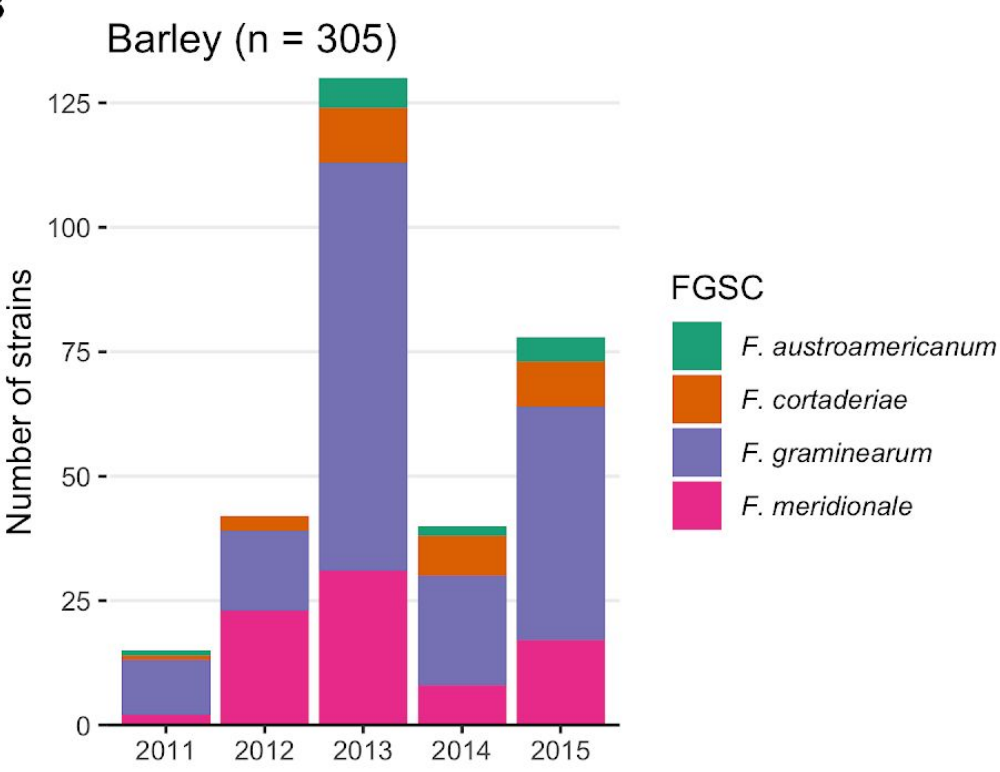

Figure 3. Number of isolates per species of the Fusarium graminearum species complex (FGSC) conditioned to year of sampling in wheat (A) and barley (B)

\section{Mycotoxin production by F. poae}

Three toxins were found in isolates of F. poae (20 from barley and 12 from wheat): 29/32 produced DAS, 24/38 produced diANIV and 20/32 produced butenolide (Table 1). Neosolaniol, T-2, or HT-2 were not detected in cultures of any of the isolates. 

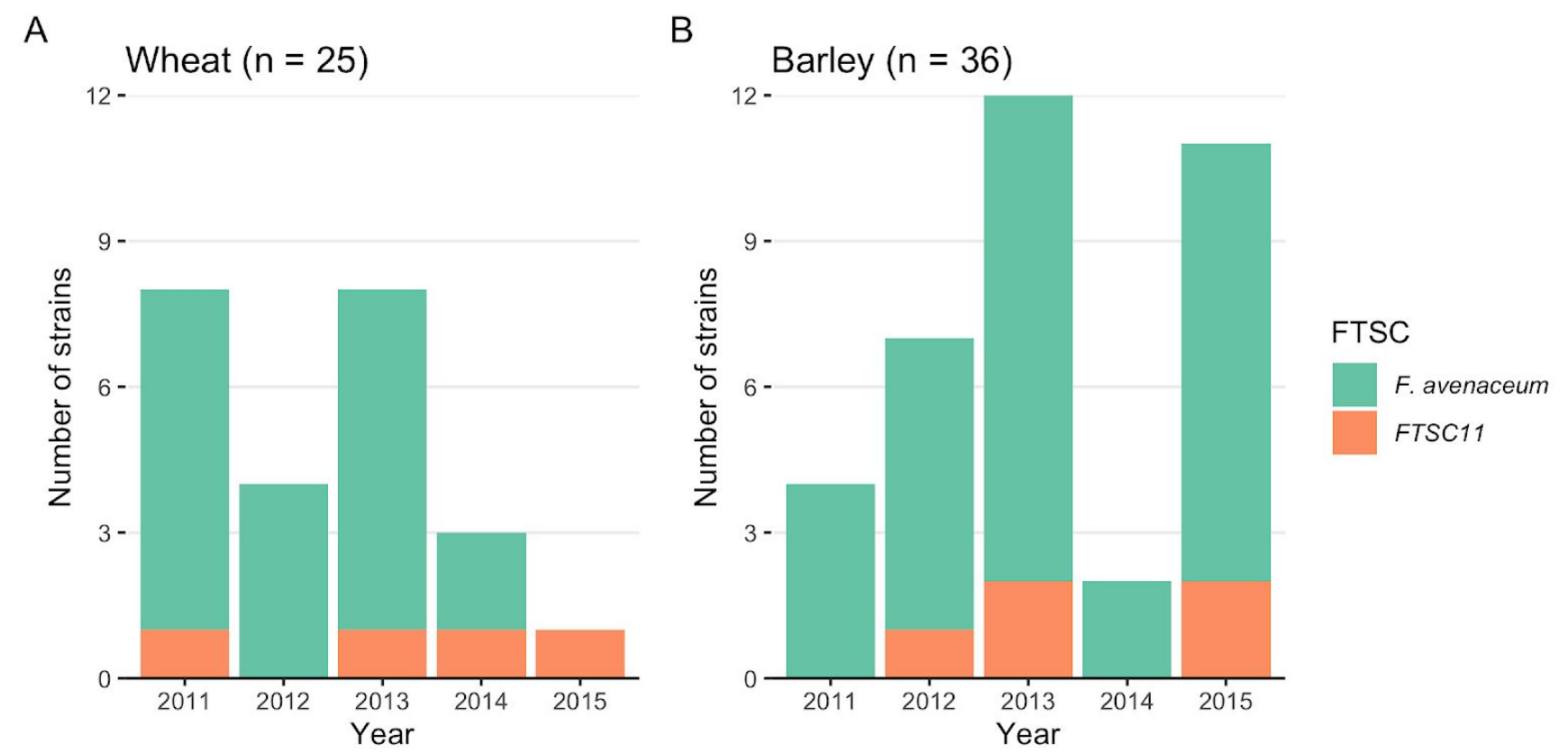

Figure 4. Number of isolates belonging to two clades of the Fusarium tricinctum species complex (FGSC) conditioned to year of sampling in wheat (A) and barley (B). A single F. acuminatum isolate was reported in wheat in 2013

\section{Mycotoxin production by FTSC}

Enniatins, moniliformin and beauvericin were detected but only the first two mycotoxins could be quantified. The frequency and concentration levels varied across the species.

F. avenaceum. All strains produced moniliformin, but not all produced the different forms of enniatins. Five out of 30 strains did not produce any form and $60 \%$ to $80 \%$ of the strains produced ENNA1, ENNB and ENNB1 at median levels ranging from 0.94 to 15.3; ENNA1 was detected at much lower concentration than ENNB and ENNB1 (Table 1).

FTSC11. Similar to the other species, all produced moniliformin. The frequency of enniatin-producing strains was similar to F. avenaceum, but the concentration levels were 
much lower especially for ENNB and ENNB1. The maximum ENNB produced by one strain was similar to the median levels produced by F. avenaceum strains.

Table 1. Summary for the mycotoxin analysis data for 42 strains of the Fusarium tricinctum species complex (FTSC) isolated from Fusarium head blight-symptomatic heads collected at wheat and barley fields in southern Brazil (Guarapuava, Paraná state) during five growing seasons (2011 to 2015)

\begin{tabular}{|c|c|c|c|c|c|c|}
\hline \multirow[t]{2}{*}{ Species } & \multirow[t]{2}{*}{ Mycotoxin } & \multirow[t]{2}{*}{ Frequency } & \multicolumn{4}{|c|}{ Mycotoxin concentration } \\
\hline & & & Mean & Median & Min & Max \\
\hline FTSC11 & Enniatin A1 & 3 & 0.40 & 0.27 & 0.10 & 0.84 \\
\hline \multirow[t]{3}{*}{9 strains } & Enniatin B & 6 & 9.78 & 8.26 & 3.99 & 19.43 \\
\hline & Enniating B1 & 4 & 1.25 & 1.02 & 0.60 & 2.38 \\
\hline & Moniliformin & 9 & 3.46 & 0.23 & 0.00 & 9.10 \\
\hline F. acuminatum & Enniatin A & 1 & 7.76 & - & - & - \\
\hline \multirow[t]{4}{*}{1 strain } & Enniatin A1 & 1 & 76.38 & - & - & - \\
\hline & Enniatin B & 1 & 103.54 & - & - & - \\
\hline & Enniatin B1 & 1 & 116.30 & - & - & - \\
\hline & Moniliformin & 1 & 3.05 & - & - & - \\
\hline F. avenaceum & Enniatin A & 1 & 0.02 & - & - & - \\
\hline \multirow[t]{4}{*}{30 strains } & Enniatin A1 & 20 & 3.57 & 0.94 & 0.15 & 22.46 \\
\hline & Enniatin B & 24 & 28.59 & 15.28 & 0.16 & 106.81 \\
\hline & Enniatin B1 & 22 & 15.51 & 3.57 & 0.36 & 146.84 \\
\hline & Moniliformin & 30 & 4.21 & 2.87 & 0.00 & 17.50 \\
\hline
\end{tabular}


The only F. acuminatum strain produced moniliformin at a concentration similar to the mean concentration levels of the other two species. All forms of enniatin were produced by this strain, including ENNA, which was produced only this strain and one F. avenaceum strain (trace levels). Finally, this F. acuminatum strain produced very high amount of ENNA compared to the other two species $(>70 \times$ higher than the median $)$ and amount of ENNB and ENNB1 similar to only two out of $30 \mathrm{~F}$. avenaceum strains that produced these toxins at level greater than $100 \times$.

\section{Discussion}

Results of this study expanded considerably our knowledge of the diversity of Fusarium species associated with FHB in wheat and barley in Brazil, in particular for a major small grain production region in South America. The Guarapuava region has not been well represented in previous surveys that identified FGSC isolates collected mainly from northern and western Paraná state (Del Ponte et al., 2015). The analysis of the total FHB diversity obtained from a multi-season collection in a new region confirmed FGSC as the main FHB pathogen, but also revealed the presence of other non-FGSC species commonly known to cause FHB in other wheat-growing regions such as F. avenaceum and related FTSC members, as well as F. poae.

FTSC species are known to prevail in temperate, higher latitude, climates such as Northern Europe and Canada (Parry et al., 1995; Bottalico and Perrone, 2002; Uhlig et al., 2007). Studies conducted at lower, still cooler, latitudes have shown the presence of FTSC in wheat. In Kentucky, five in 68 strains from wheat belonged to two FTSC species (Bec et 
al., 2015). In Mexico, $75 \%$ of 80 toxigenic isolates from wheat in the central highlands (cooler climate) belonged to F. avenaceum and a sister species (Cerón-Bustamante et al., 2018). In Brazil, two previous studies have reported FTSC in wheat and barley. A small collection of FTSC strains was isolated from symptomatic wheat and air above canopy reproduced FHB symptoms in wheat at severity levels similar to FGSC (Moreira et al., 2019). A recent survey also showed the presence of FTSC in commercial barley grain from southern Brazil (Piacentini et al., 2019). The concern with an apparent emergence of FTSC among FHB pathogens relates to their toxigenic potential. In the Mexican study, most strains produced enniatin B or chlamydosporol. These species may potentially produce moniliform, which is known to cause muscular weakness, cardiovascular problems and reduced immune function, and reduced weight grain (Uhlig et al., 2007). Our study showed that all FTSC strains, regardless of the species, were able to produce moniliformin. This is an important finding as data on grain contamination with this mycotoxin in Brazil is only available for maize as a results of F. verticillioides infection (Oliveira et al., 2017). The in planta inoculation studies conducted in cooler regions where F. avenaceum is more common such as Canada and Poland, have shown the ability of this group to produce mycotoxin in barley and wheat grains (Goliński et al., 1997; Abramson et al., 2002)

Another known FHB-causing species reported for the first time at relatively high frequency in Brazil was F. poae, which represented 11\% of the collection. F. poae is known to be a typical type B trichothecenes producer (NIV), but has also been known to produce type A trichothecene such as diacetoxyscirpenol (DAS) (O'Donnell et al., 2018). In the Americas, F. poae isolates have been found in barley and wheat from Argentina and Canada (Bourdages et al., 2006; Stenglein et al., 2012), wheat in Paraguay (Arrúa et al., 2019) and barley from Uruguay (Garmendia et al., 2018). In Europe, reports exist in Germany, Italy and other countries (Birzele et al., 2002; Xu et al., 2005; Infantino et al., 2012; Covarelli et al., 
2015). Identifications of F. poae strains based only on morphological characteristics are unreliable and may lead to inaccurate conclusions regarding the toxin production potential for this species. The species F. langsethiae is similar morphologically to F. poae, however it is more closely related to F. sporotrichioides than F. poae (Knutsen et al., 2004; Torp and Nirenberg, 2004; Wilson et al., 2004; Yli-Mattila et al., 2004) and synthesizes the trichothecenes T-2 and HT-2, toxins not usually reported for F. poae. Therefore, DNA sequence-based identifications are required, and PCR assays may provide a rapid and reliable alternative to distinguish between these two species (Stenglein, 2009)

DON and NIV have multiple adverse effects at the molecular level, such as inhibition of proteins, DNA and RNA synthesis, with NIV representing an added concern for food safety, since several reports have shown its toxicity is higher than DON (Cheat et al., 2015). The presence of NIN-producing F. poae, in addition to F. meridionale, as FHB pathogens in Brazil may represent an additional risk for wheat and barley, and could have negative effects on malting and brewing parameters (Nielsen et al., 2014). Evidence of the large diversity of species in this region may also be explained by the occurrence of opportunistic pathogens at a relatively lower frequency.

Our data suggested yearly shifts in species frequencies, especially a decrease of the dominant F. graminearum population in favor of other contributors. In 2012, F. poae prevalence peaked in barley and F. meridionale peaked in both wheat and barley. The 2012 season was relatively drier and when the FHB incidence in the non-treated plots of experiments was generally low (Feksa et al., 2019). We hypothesize that less-dominant pathogens may be more important in regions or years where weather is not favorable to $F$. graminearum outbreaks of FHB. In that context, understanding the overall spectrum of FHB pathogens and their mycotoxin potential may help inform toxin monitoring programs 
when conditions are less favorable for F. graminearum. The ecological or seasonal factors driving these fluctuations should be further investigated, as this will have important implications for food safety.

When restricting the analysis to FGSC strains, our data confirmed i) the dominance of F. graminearum of the 15-ADON type, followed by F. meridionale, of the NIV type at a frequency similar to the other regions of Paraná state, and ii) the minor role of NIV-producing isolates of F. austroamericanum and F. cortaderiae in FHB epidemics. We confirmed the role of pathogen species in shaping the composition of the trichothecene genotypes in Brazil (Astolfi et al., 2012; Del Ponte et al., 2015; Gomes et al., 2015; Kuhnem et al., 2016). Despite analyzing close to two thousand isolates from different hosts, no chemotype polymorphism within F. graminearum from Brazil (exclusively 15-ADON) has been found. This is also the first study in Brazil as well as the first analyses of FHB pathogens from wheat in South America to screen for the novel NX toxin type, which has previously been reported among F. graminearum from North America (Liang et al., 2014; Kelly et al., 2015). As was previously reported in a smaller study of barley isolates from Uruguay (Garmendia et al., 2018), the NX toxin type was not observed in Brazil.

The 3-ADON type in F. graminearum was reported for several strains in Argentina and for one isolate from Uruguay (Alvarez et al., 2009; Umpiérrez-Failache et al., 2013). In Brazil, the 3-ADON chemotype is unique to F. cortaderiae and F. austromericanum strains from wheat (Del Ponte et al., 2015) and barley (Astolfi et al., 2011; Castañares et al., 2016). This pattern seems unique compared with other intensively sampled wheat regions of North America, Europe and China. There, the dominant species, either F. graminearum or F. asiaticum, possess more than one chemotype which alternate dominance depending on the region, previous crop or year. For example, 15-ADON and 3-ADON strains of $\mathrm{F}$. 
graminearum have been found in Europe where the former is more common in the south and central (Jennings et al., 2004; Tóth et al., 2005; Talas et al., 2011; Boutigny et al., 2014) and the latter in northwestern Europe (Yli-Mattila et al., 2009; Nielsen et al., 2012; Fredlund et al., 2013). In China, F. asiaticum of the 3-ADON type has been replacing the NIV-producing populations of this species (Zhang et al., 2012). In Japan, 3-ADON and NIV chemotypes from F. asiaticum predominate in wheat (Karugia et al., 2009). In North America, 15-ADON chemotype is predominant in F. graminearum, but a high frequency of the 3-ADON chemotype isolates has been found in some parts of USA and Canada (Gale et al., 2007; Ward et al., 2008) and NIV and NX strains of F. graminearum have been reported at relatively low levels (Starkey et al. 2007; Gale et al. 2011; Schmale et al., 2012; Kelly et al., 2016). Finally, we found that NIV-producing FGSC species were more prevalent in barley than in wheat, which is in agreement with previous studies of isolates from these crops in RS state (Astolfi et al., 2012; Del Ponte et al., 2015; Machado et al., 2017).

In summary, using state of the art methods of Fusarium species identification we report a much larger diversity of toxigenic species associated with FHB in wheat and barley in a major production region of southern Brazil. F. graminearum remains as the most dominant in wheat and barley, but FTSC and F. poae are reported here for the first time as significant contributors to FHB in Brazil and may be considered emergent pathogens. In addition, but at much lower levels, we report FFSC, FOSC, FIESC, F. cerealis and a new species within the FSAMSC, namely F. subtropicale (Pereira et al., 2018). The significant temporal changes in FHB species composition could have direct impacts on the type of mycotoxins that accumulate in grain. Future mycotoxin surveys should focus on mycotoxins potentially produced by the entire spectrum of Fusarium species diversity 
reported here. The continuous monitoring of the population may be informative to clarify the reasons of the temporal variation of the population in a certain year.

\section{Acknowledgements}

This study was financed in part by the Coordenação de Aperfeiçoamento de Pessoal de Nível Superior - Brasil (CAPES) - Finance Code 001, for a scholarship for the first author, and also by the Fundação Agrária de Pesquisa Agropecuária (FAPA), Cooperativa Agrária Agroindustrial, and the Brazilian National Council for Scientific and Technological Development (CNPQ project 310719/2016-6). Funding was also provided by the USDA-ARS National Program for Food Safety. We also thank Nathan Orwig, Thomas Usgaard, Amy Kelly, and Amy McGovern for excellent assistance. Mention of trade names or commercial products in this article is solely for the purpose of providing specific information and does not imply recommendation or endorsement by the United States Department of Agriculture (USDA). USDA is an equal opportunity provider and employer.

\section{References}

Abramson, D., McCallum, B., Smith, D.M. and Tekauz, A. (2002) Moniliformin in barley inoculated with Fusarium avenaceum. Food Additives \& Contaminants, 19, 765-769.

Alvarez, C.L., Azcarate, M.P. and Pinto, V.F. (2009) Toxigenic potential of Fusarium graminearum sensu stricto isolates from wheat in Argentina. International Journal of Food Microbiology, 135, 131-135. https://doi.org/10.1016/j.ijfoodmicro.2009.07.037

Aoki, T., Vaughan, M.M., McCormick, S.P., Busman, M., Ward, T.J., Kelly, A. et al. (2015) Fusarium dactylidis sp. nov., a novel nivalenol toxin-producing species sister to F. pseudograminearum 
isolated from orchard grass (Dactylis glomerata) in Oregon and New Zealand. Mycologia, 107, 409-418.

Arrúa, A.A.A., Arrúa, J.M.M., Caza, M.C.C., Iehisa, J., Caballero, Y.M.R., Ríos, D.F. et al. (2019) First report of Fusarium poae associated with Fusarium head blight in wheat in Paraguay. Plant Disease, 103,580 .

Astolfi, P., dos Santos, J., Schneider, L., Gomes, L.B., Silva, C.N., Tessmann D.J. et al. (2011) Molecular survey of trichothecene genotypes of Fusarium graminearum species complex from barley in southern Brazil. International Journal of Food Microbiology, 148, 197-201. https://doi.org/10.1016/j.ijfoodmicro.2011.05.019

Astolfi, P., Reynoso, M.M., Ramirez, M.L., Chulze, S.N., Alves, T.C.A., Tessmann D.J. et al. (2012) Genetic population structure and trichothecene genotypes of Fusarium graminearum isolated from wheat in southern Brazil. Plant Pathology, 61, 289-295. https://doi.org/10.1111/j.1365-3059.2011.02515.x

Bec, S., Ward, T., Farman, M., O’Donnell, K., Hershman, D., Van Sanford, D. et al. (2015) Characterization of Fusarium strains recovered from wheat with symptoms of head blight in Kentucky. Plant Disease, 99, 1622-1632. https://doi.org/10.1094/PDIS-06-14-0610-RE

Birzele, B., Meier, A., Hindorf, H., Kramer, J. and Dehne, H.W. (2002) Epidemiology of Fusarium infection and deoxynivalenol content in winter wheat in the Rhineland, Germany. European Journal of Plant Pathology, 108, 667-673. https://doi.org/10.1007/978-94-010-0001-7_9

Bottalico, A. and Perrone G. (2002) Toxigenic Fusarium species and mycotoxins associated with head blight in small-grain cereals in Europe. European Journal of Plant Pathology, 108, 611-624. https://doi.org/10.1023/A:1020635214971

Bourdages, J.V., Marchand, S., Rioux, S. and Belzile, F.J. (2006) Diversity and prevalence of Fusarium species from Quebec barley fields. Canadian Journal of Plant Pathology, 28, 419-425. https://doi.org/10.1080/07060660609507315

Boutigny, A.L., Ward, T.J., Ballois, N., Iancu, G. and Ioos, R. (2014) Diversity of the Fusarium graminearum species complex on French cereals. European Journal of Plant Pathology, 138, 133-48. https://doi.org/10.1007/s10658-013-0312-6

Busman, M. (2017) Utilization of high performance liquid chromatography coupled to tandem mass spectrometry for characterization of 8-O-methylbostrycoidin production by species of the fungus Fusarium. Journal of Fungi, 3, E43. doi:10.3390/jof3030043

Busman, M., Butchko, R.A., Proctor, R.H. (2012) LC-MS/MS method for the determination of the fungal pigment bikaverin in maize kernels as an indicator of ear rot. Food Additives and Contaminants Part A, 29, 1736-1742. https://doi.org/10.1080/19440049.2012.704528

Castañares, E., Dinolfo, M.I., Del Ponte, E.M., Pan, D. and Stenglein, S.A. (2016) Species composition and genetic structure of Fusarium graminearum species complex populations affecting the main barley growing regions of South America. Plant Pathology, 65, 930-939. https://doi.org/10.1111/ppa.12470

Cerón-Bustamante, M., Ward, T.J., Kelly, A., Vaughan, M.M., McCormick, S.P., Cowger, C. et al. (2018) Regional differences in the composition of Fusarium head blight pathogens and mycotoxins 
associated with wheat in Mexico. International Journal of Food Microbiology, 273, 11-19. https://doi.org/10.1016/j.ijfoodmicro.2018.03.003

Cheat, S., Gerez, J.R., Cognie, J., Alassane-Kpembi, I., Bracarense, A.P., Raymond-Letron, I. et al. (2015). Nivalenol has a greater impact than deoxynivalenol on pig jejunum mucosa in vitro on explants and in vivo on intestinal loops. Toxins, 7, 1945-1961. https://doi.org/10.3390/toxins7061945

Covarelli, L., Beccari, G., Prodi, A., Generotti, S., Etruschi, F., Juan, C. et al. (2015). Fusarium species, chemotype characterization and trichothecene contamination of durum and soft wheat in an area of central Italy. Journal of the Science of Food and Agriculture, 95, 540-551. https://doi.org/10.1002/jsfa.6772

Del Ponte, E.M., Fernandes, J.M.C. and Bergstrom, G.C. (2007) Influence of growth stage on Fusarium head blight and deoxynivalenol production in wheat. Journal of Phytopathology, 155, 577-581. https://doi.org/10.1111/j.1439-0434.2007.01281.x

Del Ponte, E.M., Spolti, P., Ward, T.J., Gomes, L.B., Nicolli, C.P., Kuhnem P.R. et al. (2015). Regional and field-specific factors affect the composition of Fusarium head blight pathogens in subtropical no-till wheat agroecosystem of Brazil. Phytopathology, 105, 246-254. https://doi.org/10.1094/PHYTO-04-14-0102-R

Feksa, H.R., Do Couto, H.T.Z., Garozi, R., De Almeida, J.L., Gardiano, C.G., Tessmann D.J. (2019) Preand post-infection application of strobilurin-triazole premixes and single fungicides for control of fusarium head blight and deoxynivalenol mycotoxin in wheat. Crop Protection, 117, 128-134. https://doi.org/10.1016/j.cropro.2018.12.003

Fredlund, E., Gidlund, A., Sulyok, M., Börjesson, T., Krska, R., Olsen, M. et al. (2013) Deoxynivalenol and other selected Fusarium toxins in Swedish oats-occurrence and correlation to specific Fusarium species. International Journal of Food Microbiology, 167, 276-283. https://doi.org/10.1016/j.ijfoodmicro.2013.06.026

Geiser, D.M., del Mar Jiménez-Gasco, M., Kang, S., Makalowska, I., Veeraraghavan, N., Ward, T.J. et al. (2004) FUSARIUM-ID v. 1.0: a DNA sequence database for identifying Fusarium. European Journal of Plant Pathology, 110, 473-479. https://doi.org/10.1023/B:EJPP.0000032386.75915.a0

Gale, L.R., Ward, T.J., Balmas, V., Kistler, H.C. (2007) Population subdivision of Fusarium graminearum sensu stricto in the upper Midwestern United States. Phytopathology, 97, 1434-1439. https://doi.org/10.1094/PHYTO-97-11-1434

Gale, L.R., Harrison, S.A., Ward, T.J., O'Donnell, K., Milus, E. A., Gale, S. W. et al. (2011) Nivalenol-type populations of Fusarium graminearum and F. asiaticum are prevalent on wheat in southern Louisiana. Phytopathology, 101, 124-134. https://doi.org/10.1094/PHYTO-03-10-0067.

Gardiner, D.M., Kazan, K., Manners, J.M. (2009) Nutrient profiling reveals potent inducers of trichothecene biosynthesis in Fusarium graminearum. Fungal Genetics and Biology, 46, 604-613. https://doi.org/10.1016/j.fgb.2009.04.004

Garmendia, G., Pattarino, L., Negrín, C., Martínez-Silveira, A., Pereyra, S., Ward, T.J. et al. (2018) Species composition, toxigenic potential and aggressiveness of Fusarium isolates causing Head 
blight of barley in Uruguay. Food Microbiology, 76, 426-433. https://doi.org/10.1016/j.fm.2018.07.005

Goliński, P., Kostecki, M., Kaptur, P., Wojciechowski, S., Kaczmarek, Z., Wiśniewska, H. et al. (1997) Fusarium head blight and moniliformin accumulation in kernels of 18 winter wheat cultivars inoculated with Fusarium avenaceum (3 years study). Cereal Research Communications, 25, 673-675.

Gomes, L., Ward, T., Badiale-Furlong, E. and Del Ponte, E. (2015) Species composition, toxigenic potential and pathogenicity of Fusarium graminearum species complex isolates from southern Brazilian rice. Plant Pathology, 64, 980-987. https://doi.org/10.1111/ppa.12332

Goswami, R.S. and Kistler, H.C. (2004) Heading for disaster: Fusarium graminearum on cereal crops. Molecular Plant Pathology, 5, 515-525. https://doi.org/10.1111/j.1364-3703.2004.00252.x

Gräfenhan, T., Patrick, S.K., Roscoe, M., Trelka, R., Gaba, D., Chan, J.M. et al. (2013) Fusarium damage in cereal grains from western Canada. 1. Phylogenetic analysis of moniliformin-producing Fusarium species and their natural occurrence in mycotoxin-contaminated wheat, oats, and rye. Journal of Agricultural and Food Chemistry, 61, 5425-5437. https://doi.org/10.1021/jf400651p

Hepperle, D. (2004) SeqAssem. A sequence analysis tool, contig assembler and trace data visualization tool for molecular sequences. Win32-Version. Distributed by the author via: http://www.sequentix.de.

Infantino, A., Santori, A. and Shah, D.A. (2012) Community structure of the Fusarium complex on wheat seed in Italy. European Journal of Plant Pathology, 132, 499-510. https://doi.org/10.1007/s10658-011-9892-1

Jennings, P., Coates, M.E., Turner, J.A., Chandler, E.A. and Nicholson, P. (2004) Determination of deoxynivalenol and nivalenol chemotypes of Fusarium culmorum isolate from England and Wales by PCR assay. Plant Pathology, 53, 182-90. https://doi.org/10.1111/j.0032-0862.2004.00985.x

Jestoi, M. (2008) Emerging Fusarium-mycotoxins fusaproliferin, beauvericin, enniatins, and moniliformin - a review. Critical Reviews in Food Science and Nutrition, 48, 21-49. https://doi.org/10.1080/10408390601062021

Karugia, G.W., Suga, H., Gale, L.R., Nakajima, T., Ueda, A. and Hyakumachi, M. (2009). Population structure of Fusarium asiaticum from two Japanese regions and eastern China. Journal of General Plant Pathology, 75, 110-118. https://doi.org/10.1007/s10327-009-0153-5

Kelly, A.C., Clear, R.M., O’Donnell, K., McCormick, S., Turkington, T.K., Tekauz, A. et al. (2015) Diversity of Fusarium head blight populations and trichothecene toxin types reveals regional differences in pathogen composition and temporal dynamics. Fungal Genetics and Biology, 82, 22-31. https://doi.org/10.1016/j.fgb.2015.05.016

Kelly, A.C., Proctor, R.H., Belzile, F., Chulze, S.N., Clear, R.M., Cowger, C. et al (2016). The geographic distribution and complex evolutionary history of the NX-2 trichothecene chemotype from Fusarium graminearum. Fungal Genetics and Biology, 95, 39-48. https://doi.org/10.1016/j.fgb.2016.08.003

Knutsen, A.K., Torp, M. and Holst-Jensen, A. (2004) Phylogenetic analyses of the Fusarium poae, F. sporotrichioides and F. langsethiae species complex based on partial sequences of the translation 
elongation factor-1 alpha gene. International Journal of Food Microbiology, 95, 287-295. https://doi.org/10.1016/j.ijfoodmicro.2003.12.007

Kuhnem, P.R., Del Ponte, E.M., Dong, Y. and Bergstrom, G.C. (2015) Fusarium graminearum isolates from wheat and maize in New York show similar range of aggressiveness and toxigenicity in cross-species pathogenicity tests. Phytopathology, 105, 441-448. https://doi.org/10.1094/PHYTO-07-14-0208-R

Kuhnem, P.R., Ward, T.J., Silva, C.N., Spolti, P., Ciliato, M.L., Tessmann, D.J. et al. (2016) Composition and toxigenic potential of the Fusarium graminearum species complex from maize ears, stalks and stubble in Brazil. Plant Pathology, 65, 1185-1191. https://doi.org/10.1111/ppa.12497

Kumar, S., Stecher, G., Li, M., Knyaz, C. and Tamura, K. (2018) MEGA X: molecular evolutionary genetics analysis across computing platforms. Molecular Biology and Evolution, 35, 1547-1549. https://doi.org/10.1093/molbev/msy096

Leslie, J.F. and Summerell, B.A. (2006) The Fusarium Laboratory Manual. Ames, IA: Blackwell Publishing.

Liang, J. M., Xayamongkhon, H., Broz, K., Dong, Y., McCormick, S. P., Abramova, S. et al. (2014) Temporal dynamics and population genetic structure of Fusarium graminearum in the upper Midwestern United States. Fungal Genetics and Biology, 73, 83-92. https://doi.org/10.1016/j.fgb.2014.10.002

Luz, C., Saladino, F., Luciano, F.B., Mañes, J. and Meca, G. (2017) Occurrence, toxicity, bioaccessibility and mitigation strategies of beauvericin, a minor Fusarium mycotoxin. Food and Chemical Toxicology, 107, 430-439. https://doi.org/10.1016/j.fct.2017.07.032

Lysøe, E., Harris, L.J., Walkowiak, S., Subramaniam, R., Divon, H.H., Riiser, E.S. et al. 2014. The genome of the generalist plant pathogen Fusarium avenaceum is enriched with genes involved in redox, signaling and secondary metabolism. PLoS One, 9, e112703. https://doi.org/10.1371/journal.pone.0112703

Machado, F.J., Nicolli, C.P., Möller, P.A., Arruda, R., Ward, T.J. and Del Ponte, E.M. (2017). Differential triazole sensitivity among members of the Fusarium graminearum species complex infecting barley grains in Brazil. Tropical Plant Pathology, 42, 197-202. https://doi.org/10.1007/s40858-017-0158-0

McMullen, M., Bergstrom, G., De Wolf, E., Dill-Macky, R., Hershman, D., Shaner, G., et al. (2012) A unified effort to fight an enemy of wheat and barley: Fusarium head blight. Plant Disease, 96, 1712-1728. https://doi.org/10.1094/PDIS-03-12-0291-FE

Moreira, G. M., Machado, F. J., Pereira, C. B., Neves, D. L., Tessmann, D. J. et al. (2020) First report of the Fusarium tricinctum species complex causing Fusarium head blight of wheat in Brazil. Plant Disease, 104, 586-586. https://doi.org/10.1094/PDIS-03-19-0552-PDN

Nielsen, L.K., Cook, D.J., Edwards, S.G. and Ray, R.V. (2014). The prevalence and impact of Fusarium head blight pathogens and mycotoxins on malting barley quality in UK. International Journal of Food Microbiology, 179, 38-49. https://doi.org/10.1016/j.ijfoodmicro.2014.03.023

Nielsen, L.K., Jensen, J.D., Rodríguez, A., Jørgensen, L.N. and Justesen, A.F. (2012) TRI12 based quantitative real-time $\mathrm{PCR}$ assays reveal the distribution of trichothecene genotypes of $\mathrm{F}$. 
graminearum and F. culmorum isolates in Danish small grain cereals. International Journal of Food Microbiology, 157, 384-392. https://doi.org/10.1016/j.ijfoodmicro.2012.06.010

Niessen, L., Gräfenhan, T. and Vogel, R.F. (2012) ATP citrate lyase 1 (acl1) gene-based loop mediated amplification assay for the detection of the Fusarium tricinctum species complex in pure cultures and in cereal samples. International Journal of Food Microbiology, 158, 171-185. https://doi.org/10.1016/j.ijfoodmicro.2012.06.021

O’Donnell, K., Cigelnik, E. and Nirenberg, H.I. (1998) Molecular systematics and phylogeography of the Gibberella fujikuroi species complex. Mycologia, 90, 465-493. https://doi.org/10.2307/3761407

O’Donnell, K., McCormick, S.P., Busman, M., Proctor, R.H., Ward, T.J., Doehring, G., et al. (2018). Marasas et al. 1984 "Toxigenic Fusarium species: identity and mycotoxicology" revisited. Mycologia, 110, 1-23. https://doi.org/10.1080/00275514.2018.1519773

O’Donnell, K., Sutton, D.A., Rinaldi, M.G., Sarver, B.A.J., Balaje, S.A., Summerell, R.C. et al. (2010) Internet-accessible DNA sequence database for identifying fusaria from human and animal infections. Journal of Clinical Microbiology, 48, 3708-3718. https://doi.org/10.1128/JCM.00989-10

O'Donnell, K., Humber, R.A., Geiser, D.M., Kang, S., Park, B., Robert, V.A.R.G. et al. (2012). Phylogenetic diversity of insecticolous fusaria inferred from multilocus DNA sequence data and their molecular identification via FUSARIUM-ID and Fusarium MLST. Mycologia, 104, 427-445. https://doi.org/10.3852/11-179

O'Donnell, K., Rooney, A.P., Proctor, R.H., Brown, D.W., McCormick, S.P., Ward, T.J., et al. (2013) Phylogenetic analyses of RPB1 and RPB2 support a middle Cretaceous origin for a clade comprising all agriculturally and medically important fusaria. Fungal Genetics and Biology, 52, 20-31. https://doi.org/10.1016/j.fgb.2012.12.004

Oliveira, M.S., Rocha, A., Sulyok, M., Krska, R. and Mallmann, C.A. (2017) Natural mycotoxin contamination of maize (Zea mays L.) in the South region of Brazil. Food Control, 73, 127-132.

Parry, D.W., Jenkinson, P. and McLeod, L. (1995) Fusarium ear blight (scab) in small-grain cereals-A review. Plant Pathology, 44, 207-238. https://doi.org/10.1111/j.1365-3059.1995.tb02773.x

Pereira, C.B., Ward, T.J., Tessmann, D.J., Del Ponte, E.M., Laraba, I., Vaughan, M.M. et al. (2018). Fusarium subtropicale, sp. nov., a novel nivalenol mycotoxin-producing species isolated from barley (Hordeum vulgare) in Brazil and sister to F. praegraminearum. Mycologia, 10, 1-12. https://doi.org/10.1080/00275514.2018.1512296

Piacentini, K.C., Rocha, L.O., Savi, G.D., Carnielli-Queiroz, L., Fontes, L.C. and Correa, B. (2019) Assessment of toxigenic Fusarium species and their mycotoxins in brewing barley grains. Toxins, 11, 31. https://doi.org/10.3390/toxins11010031

R Core Team (2018) R: A language and environment for statistical computing. R Foundation for Statistical Computing,Vienna, Austria. URL https://www.R-project.org/.

Savard, M.E. and Blackwell, B.A. (1994) Spectral characteristic of secondary metabolites from Fusarium fungi. In: Miller, J.D. and Trenholm, H.L. (Eds.) Mycotoxins in Grain: Compounds Other Than Aflatoxin. Saint Paul, MN: Eagan Press, pp. 59-260. 
Schmale, D.G., Ross, S.D., Fetters, T.L., Tallapragada, P., Wood-Jones, A.K. and Dingus, B. (2012) Isolates of Fusarium graminearum collected 40-320 meters above ground level cause Fusarium head blight in wheat and produce trichothecene mycotoxins. Aerobiologia, 28, 1-11. https://doi.org/10.1007/s10453-011-9206-2

Scoz, L.B., Astolfi, P., Reartes, D.S., Schmale, D.G.III., Moraes, M.G. and Del Ponte, E.M. (2009) Trichothecene mycotoxin genotypes of Fusarium graminearum sensu stricto and Fusarium meridionale in wheat from southern Brazil. Plant Pathology, 58, 344-351. https://doi.org/10.1111/j.1365-3059.2008.01949.x

Starkey, D. E., Ward, T. J., Aoki, T., Gale, L. R., Kistler, H. C., Geiser, D. M. et al. (2007) Global molecular surveillance reveals novel Fusarium head blight species and trichothecene toxin diversity. Fungal genetics and biology, 44, 1191-1204. https://doi.org/10.1016/j.fgb.2007.03.001

Stenglein, S.A. (2009) Fusarium poae: a pathogen that needs more attention. Journal of Plant Pathology, 91, 25-36. https://www.jstor.org/stable/41998571

Stenglein, S.A., Dinolfo, M.I., Bongiorno, F. and Moreno, M.V. (2012) Response of wheat (Triticum spp.) and barley (Hordeum vulgare) to Fusarium poae. Agrociencia, 46, 299-306.

Stevens, R.R. (1974) Mycology Guidebook. Seattle, WA: University of Washington Press.

Talas, F., Parzies, H.K. and Miedaner, T. (2011) Diversity in genetic structure and chemotype composition of Fusarium graminearum sensu stricto populations causing wheat head blight in individual fields in Germany. European Journal of Plant Pathology, 131, 39-48. https://doi.org/10.1007/s10658-011-9785-3

Torp, M. and Nirenberg, H.I. (2004) Fusarium langsethiae sp. nov. on cereals in Europe. International Journal of Food Microbiology, 95, 247-256. https://doi.org/10.1016/j.ijfoodmicro.2003.12.014

Tóth, B., Mesterházy, Á., Horváth, Z., Bartók, T., Varga, M. and Varga, J. (2005) Genetic variability of central European isolates of the Fusarium graminearum species complex. European Journal of Plant Pathology, 113, 35-45. https://doi.org/10.1007/s10658-005-0296-y

Uhlig, S., Jestoi, M. and Parikka, P. (2007) Fusarium avenaceum - the North European situation. International Journal of Food Microbiology, $\quad 119, \quad 17-24$. https://doi.org/10.1016/j.ijfoodmicro.2007.07.021

Umpiérrez-Failache, M., Garmendia, G., Pereyra, S., Rodríguez Haralambides, A., Ward, T.J. and Vero, S. (2013) Regional differences in species composition and toxigenic potential among Fusarium head blight isolates from Uruguay indicate a risk of nivalenol contamination in new wheat production areas. International Journal of Food Microbiology, 166, 135-140. https://doi.org/10.1016/j.ijfoodmicro.2013.06.029

Vanheule, A., De Boevre, M., Moretti, A., Scauflaire, J., Munaut, F., De Saeger, S. et al. (2017) Genetic divergence and chemotype diversity in the Fusarium head blight pathogen Fusarium poae. Toxins, 9, 255. https://doi.org/10.3390/toxins9090255.

Varga, E., Wiesenberger, G., Hametner, C., Ward, T. J., Dong, Y., Schöfbeck, D. et al. (2015) New tricks of an old enemy: isolates of Fusarium graminearum produce a type A trichothecene mycotoxin. Environmental microbiology, 17, 2588-2600. https://doi.org/10.1111/1462-2920.12718 
Ward, T.J., Bielawski, J.P., Kistler, H.C., Sullivan, E. and O’Donnell, K. (2002) Ancestral polymorphism and adaptive evolution in the trichothecene mycotoxin gene cluster of phytopathogenic Fusarium. Proceedings of the national academy of sciences of the United States of America, 99, 9278-9283. https://doi.org/10.1073/pnas.142307199

Ward, T.J., Clear, R.M., Rooney, A.P., O'Donnell, K., Gaba, D., Patrick, S. et al. (2008) An adaptive evolutionary shift in Fusarium head blight pathogen populations is driving the rapid spread of more toxigenic Fusarium graminearum in North America. Fungal Genetics and Biology, 45, 473-484. https://doi.org/10.1016/j.fgb.2007.10.003

Wilson, A., Simpson, D., Chandler, E., Jennings, P. and Nicholson, P. (2004) Development of PCR assays for the detection and differentiation of Fusarium sporotrichioides and Fusarium langsethiae. FEMS Microbiology Letters, 233, 69-76. https://doi.org/10.1016/j.femsle.2004.01.040

Xu, X., Parry, D., Nicholson, P., Thomsett, M., Simpson, D., Edwards, S. et al. (2005) Predominance and association of pathogenic fungi causing Fusarium ear blight in wheat in four European countries. European Journal of Plant Pathology, 112, 143-154. https://doi.org/10.1007/s10658-005-2446-7

Yli-Mattila, T., Gagkaeva, T., Ward, T.J., Aoki, T., Kistler, H.C. and O’Donnell, K. (2009) A novel Asian clade within the Fusarium graminearum species complex includes a newly discovered cereal head blight pathogen from the Russian Far East. Mycologia, 101, 841-852. https://doi.org/10.3852/08-217

Yli-Mattila, T., Mach, R.L., Alekhina, I.A., Bulat, S.A., Koskinen, S., Kullnig-Gradinger, C.M. et al. (2004) Phylogenetic relationship of Fusarium langsethiae to Fusarium poae and Fusarium sporotrichioides as inferred by IGS, ITS, b-tubulin sequences and UP-PCR hybridization analysis. International Journal of Food Microbiology, 285. https://doi.org/10.1016/j.ijfoodmicro.2003.12.006

Yoshida, M. and Nakajima, T. (2010) Deoxynivalenol and nivalenol accumulation in wheat infected with Fusarium graminearum during grain development. Phytopathology, 100, 763-773. https://doi.org/10.1094/PHYTO-100-8-0763

Zhang, H., Van der Lee, T., Waalwijk, C., Chen, W.Q., Xu, J., Xu, J.S. et al. (2012) Population analysis of the Fusarium graminearum species complex from wheat in China show a shift to more aggressive isolates. PLoS One, 7, e31722. https://doi.org/10.1371/journal.pone.0031722 